\title{
Microstructure and mechanical behavior of ultrafine-grained Ni processed by different powder metallurgy methods
}

\author{
J. Gubicza ${ }^{\text {a) }}$ \\ Department of Materials Physics, Eötvös University, Budapest H-1117, Hungary

\begin{abstract}
H-Q. Bui, F. Fellah, and G.F. Dirras
Laboratoire des Propriétés Mécaniques et Thermodynamiques des Matériaux-Centre National de la Recherche Scientifique, Université Paris 13, 93430 Villetaneuse, France
\end{abstract}

(Received 23 July 2008; accepted 29 September 2008)

\begin{abstract}
Ultrafine-grained samples were produced from a Ni nanopowder by hot isostatic pressing (HIP) and spark plasma sintering (SPS). The microstructure and mechanical behavior of the two specimens were compared. The grain coarsening observed during the SPS procedure was moderated due to a reduced temperature and time of consolidation compared with HIP processing. The smaller grain-size and higher nickel-oxide content in the SPS-processed sample resulted in a higher yield strength. Compression experiments showed that the specimen produced by SPS reached a maximal flow stress at a small strain, which was followed by a long steady-state softening while the HIP-processed sample hardened until failure. It was revealed that the softening of the SPS-processed sample resulted from microcracking along the grain boundaries.
\end{abstract}

\section{INTRODUCTION}

Bulk ultrafine-grained (UFG) materials can be synthesized in two essentially different ways. The first one is a "top-down" approach, where the bulk coarse-grained materials are refined by severe plastic deformation (SPD). ${ }^{1-4}$ The second way for producing ultrafinegrained materials is a "bottom-up" approach, when samples are assembled from individual atoms or nanoparticles. ${ }^{5-7}$ Most bottom-up methods first produce nanopowders, which need to be consolidated in a second step. The ultrafine-grained microstructures obtained by powder sintering are less textured compared with the SPDprocessed materials. At the same time, the sintered materials often have undesired contamination and remaining porosity. ${ }^{8}$ To avoid porosity, sintering is usually carried out at elevated temperatures, such as in hot isostatic pressing (HIP), which usually results in grain coarsening. ${ }^{9}$ The grain growth can be moderated by optimizing the compaction parameters (temperature, pressure, and the duration of sintering), e.g., in spark plasma sintering (SPS), where the consolidation is assisted by electric current pulses. ${ }^{10-12}$ The physics of the consolidation process during SPS processing is not fully understood,

\footnotetext{
a) Address all correspondence to this author.

e-mail: gubicza@metal.elte.hu

Dedicated to Professor Georges Saada on the occasion of his award

"Grande Médaille, 2008" of the French Society of Metallurgy and Materials for his achievements in Physical Metallurgy.

DOI: 10.1557/JMR.2009.0010
}

but its main characteristic is an ultrafast compaction at much lower temperatures than in the classic techniques, thus reducing grain growth. ${ }^{13}$ The study of the correlation between microstructure and mechanical behavior of bulk UFG samples produced by different powder metallurgy procedures is of great importance for practical applications. In this article, the microstructures and the mechanical properties of ultrafine-grained $\mathrm{Ni}$ samples processed by SPS and HIP methods are compared. The difference in the deformation behavior of the samples is related to the different microstructures.

\section{EXPERIMENTAL}

A Ni nanopowder with the nominal particle size of $100 \mathrm{~nm}$ was supplied by the Argonide Corporation (Sanford, FL). The powder was produced by electroexplosion of Ni wires. ${ }^{14,15}$ The powder is supplied in high vacuum-sealed glass capsules to avoid oxidation. Each capsule contained $100 \mathrm{~g}$ of $\mathrm{Ni}$ nanopowder. The powder was consolidated using HIP and SPS methods. Before HIP processing, the glass containing the powder was broken in a glove-box under Ar atmosphere and subsequently encapsulated in a steel can and sealed under inert gas (Ar) flow to prevent oxidation. It takes approximately 1 week to remove the gas that was introduced during the encapsulation step. During HIP processing, the capsule was subjected to a pressure of $140 \mathrm{MPa}$ at $700{ }^{\circ} \mathrm{C}$ for $150 \mathrm{~min}$. In the first step of SPS processing, the capsule containing the powder was 
broken in air and rapidly transferred to a graphite mould. During the SPS procedure, the powder was held under a pressure of $150 \mathrm{MPa}$ at $500{ }^{\circ} \mathrm{C}$ for $1 \mathrm{~min}$ while pulses of high current density (of the order of $1000 \mathrm{~A} /$ $\mathrm{cm}^{2}$ ) were applied to the sample to promote consolidation. The most important advantage of the latter method is that the compaction occurs more quickly and at lower temperatures than in the classic techniques (e.g., HIP), thus preventing grain growth.

The densities of the sintered samples were determined by the Archimedes-method. The densities relative to the value of bulk pure $\mathrm{Ni}$ are $95.5 \pm 0.1$ and $95.4 \pm 0.1 \%$ for the HIP- and SPS-processed samples, respectively. This means that the remaining porosity is nearly the same for both samples. The phase composition was studied by x-ray diffraction using a Philips Xpert powder diffractometer (Eindhoven, The Netherlands) with $\mathrm{CuK} \alpha$ radiation.

The microstructure of the consolidated samples was investigated by $\mathrm{x}$-ray line profile analysis. The $\mathrm{x}$-ray line profiles were measured by a high-resolution rotating anode diffractometer (Nonius FR591, Delft, The Netherlands) using $\mathrm{CuK} \alpha_{1}$ radiation. The scattered $\mathrm{X}$-rays were detected by imaging plates with an angular resolution of $0.005^{\circ}$ in $2 \Theta$, where $\Theta$ is the angle of diffraction. The line profiles of $\mathrm{Ni}$ phase were evaluated using the extended Convolutional Multiple Whole Profile fitting procedure described in detail in other reports. ${ }^{16,17}$ This method gives the dislocation density and the twin-fault probability with good statistics. The microstructure of the bulk samples was also investigated using a JEOL-2011 transmission electron microscope (TEM; Tokyo, Japan) operating at $200 \mathrm{kV}$ and equipped with a Gatan energy filter system (Pleasanton, CA). The TEM sample was thinned mechanically first to approximately $50 \mu \mathrm{m}$ and finally with a Gatan Ion Polishing System until perforation. The distribution of the grain boundary misorientation was measured by electron backscatter diffraction (EBSD) conducted on a conventional LEO S360 scanning electron microscope (SEM; Oberkochen, Germany). The scans covered a region of approximately $50 \times 50 \mu \mathrm{m}$ using a step size between neighboring measurement positions of $0.1 \mu \mathrm{m}$. Misorientation across boundaries was determined using the software OIM version 4 produced by TexSEM Laboratories (TSL; Draper, UT).

The mechanical behavior of the sintered samples was studied by compression test (using an Instron Universal Testing Machine, model 1195; Bucks, UK) at room temperature and at a strain rate of $10^{-4} \mathrm{~s}^{-1}$. The dimensions of the samples subjected to compression were $3 \times 3 \times 5$ $\mathrm{mm}^{3}$. The strain was calculated from the crosshead displacement corrected by the elastic stiffness of the testing machine. The surfaces of the compressed samples were investigated using a LEO S440 SEM.

\section{RESULTS}

Figure 1(a) shows a TEM image taken from the initial powder. It reveals that the powder particles have spherical shape and the characteristic lattice defects inside the particles are twins. The twin fault probability is defined as the fraction of the faulted $\{111\}$ planes along their normal vector and determined as the percentage ratio of the $\{111\}$ lattice spacing and the average spacing between twin boundaries. The twin probability in the initial powder estimated roughly from TEM images is approximately 2 to $3 \%$. The particle-size distribution that was obtained from TEM is plotted in Fig. 1(b). The average particle size that was determined from this distribution is $80 \mathrm{~nm}$. It should be noted that particles larger than $1 \mu \mathrm{m}$ were scarcely detected by TEM in the initial powder, but these particles were not included in the size distribution plotted in Fig. 1(b) for the better visibility of its nanosized fraction. The energy-filtered TEM (EFTEM) images in Figs. 1(c) and 1(d) show the element maps for nickel and oxygen, respectively. It can be seen that there is a significant amount of oxygen in the surface layer (approximately 2-nm thick) of the particles in the initial powder when it was exposed to air. The traces of oxygen seen inside the particles may be a projected image of the top and bottom surfaces of the particles. The x-ray diffraction patterns in Fig. 2 show that in addition to the main $\mathrm{Ni}$ phase, $\mathrm{NiO}$ is also identified both in the powder and the bulk samples. It is suggested that the oxygen that was detected in the initial powder particles is actually contained in the $\mathrm{NiO}$ phase. To compare the $\mathrm{NiO}$ phase content in the different samples, the integrated intensity ratio of the $\mathrm{NiO}$ and $\mathrm{Ni}$ peaks at $2 \Theta=37.4^{\circ}$ and $44.6^{\circ}$, respectively, was determined and listed in Table I. It should be noted that this ratio does not give the $\mathrm{NiO}$ phase content in the samples, it is only proportional to the volume fraction of the $\mathrm{NiO}$ phase. The intensity ratio for the initial powder was found to be $0.5 \%$, which does not change during HIP processing as a result of the careful isolation of the sample from air. On the other hand, the SPS procedure results in a material having significantly higher oxide content (the intensity ratio is $0.9 \%$ ), which can be attributed to the powder processing in air before consolidation.

Figures 3(a) and 3(b) show TEM images that were obtained on the HIP- and SPS-processed samples, respectively. The grain-size distributions that were determined from TEM are presented in Figs. 3(c) and 3(d). The mean grain size that was obtained from TEM images as well as the dislocation density and the twinfault probability that was determined by an x-ray line profile analysis are listed in Table I. The mean grain size for the HIP- and SPS-processed samples were 403 and $294 \mathrm{~nm}$, respectively. The mean grain-size values for the consolidated samples are 4 to 5 times larger than the 


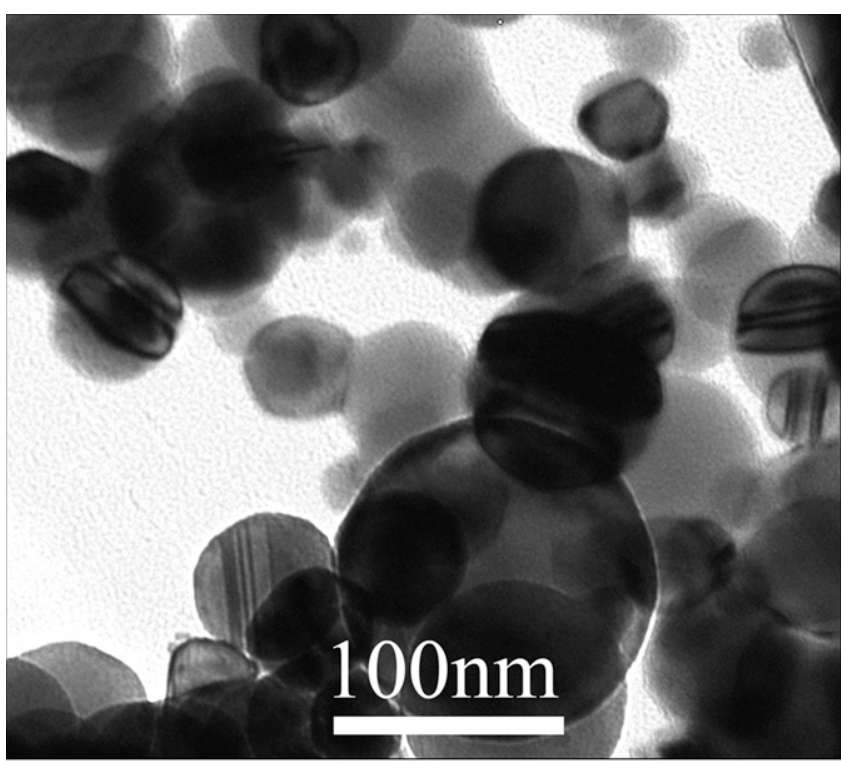

(a)

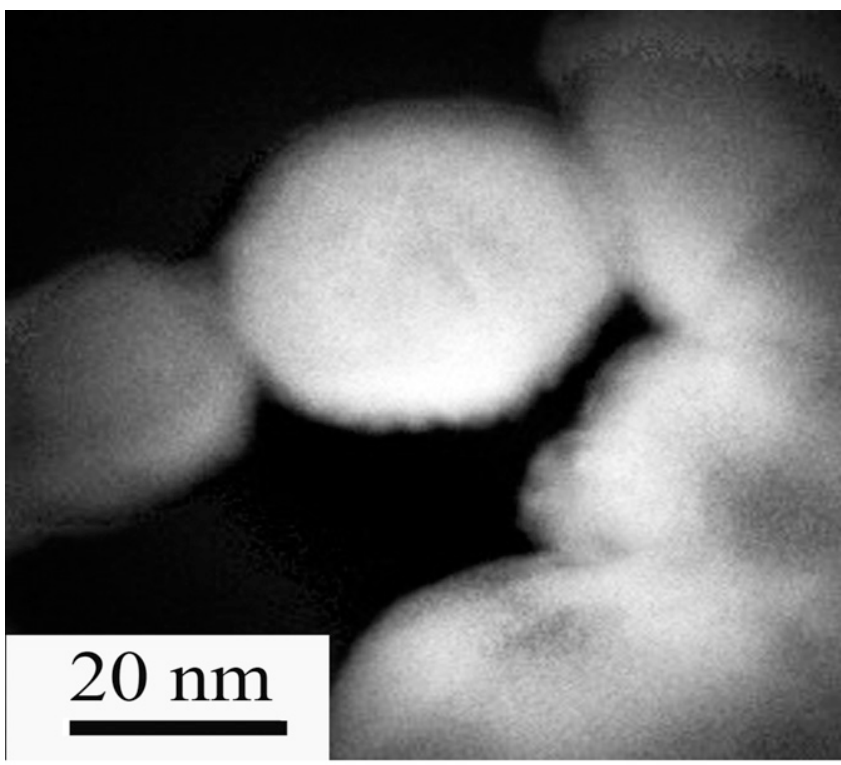

(c)

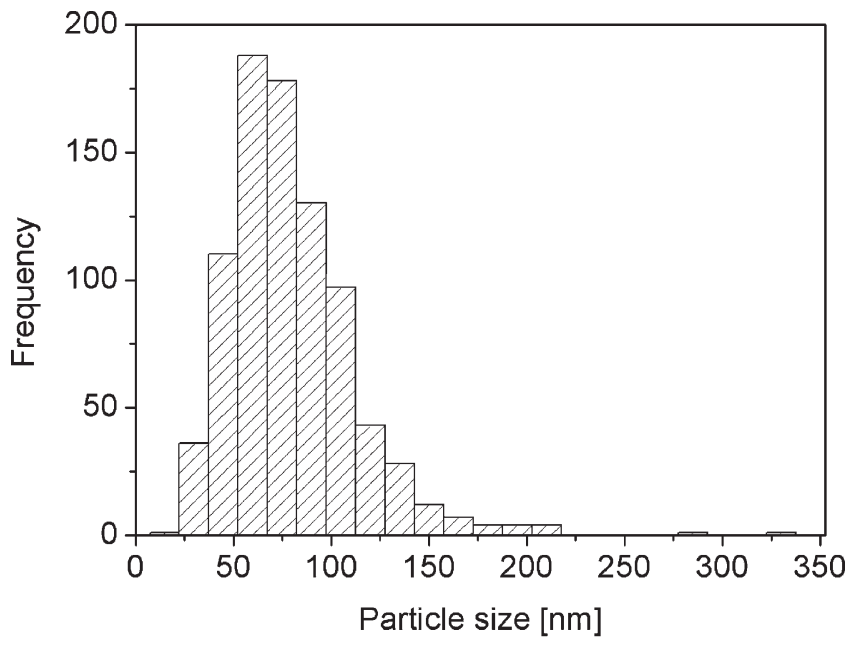

(b)

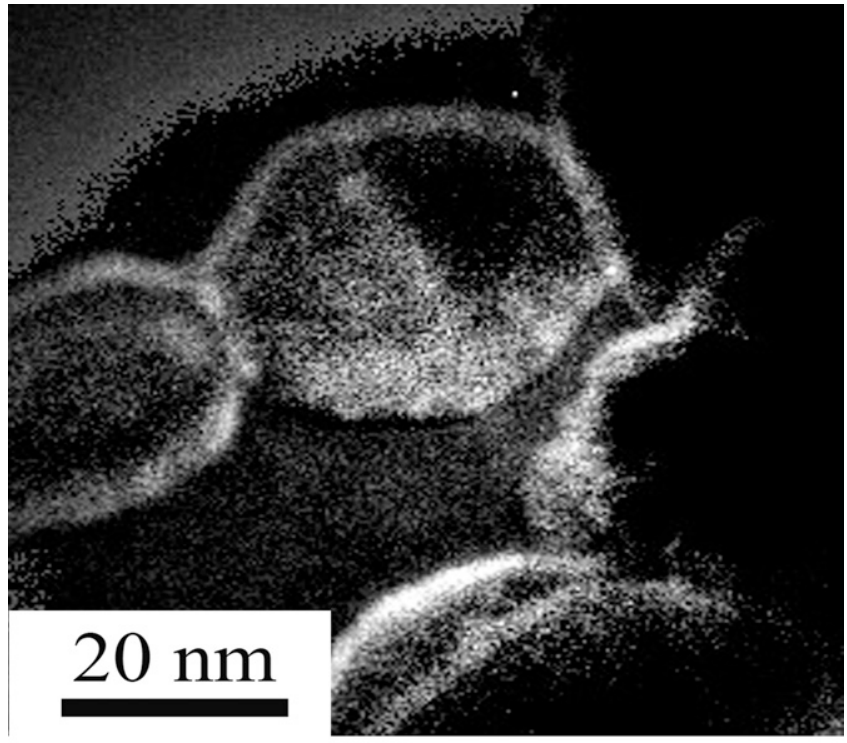

(d)

FIG. 1. (a) Bright-field TEM image for the initial powder. The particle size distribution obtained from TEM images is shown in (b). EFTEM images in (c) and (d) show the element maps for nickel and oxygen, respectively. The lighter the color in (c) and (d), the higher the local nickel and oxygen contents, respectively.

mean particle size of the initial powder, which indicates that the high temperature consolidation results in a grain coarsening. The smaller grain size in the specimen produced by SPS is attributed to the lower temperature and the shorter duration of processing, which reduced the grain-growth during consolidation. The higher degree of oxidation of the particle surfaces during SPS may also have a retarding effect on grain coarsening during consolidation. TEM and $\mathrm{x}$-ray line profile analysis show that the twin-fault probability decreases from $2-3$ to $0.2-$ $0.3 \%$ during sintering either by the HIP or SPS method (see Table I). At the same time, although dislocations were not observed in the initial powder by TEM, after consolidation a significant amount of dislocations $\left(5-6 \times 10^{14} \mathrm{~m}^{-2}\right)$ were detected by the evaluation of $\mathrm{x}$-ray line profiles. It should be noted that $\mathrm{x}$-ray line profile analysis was not performed on the initial powder because the intensity in the Debye-Scherrer rings was 

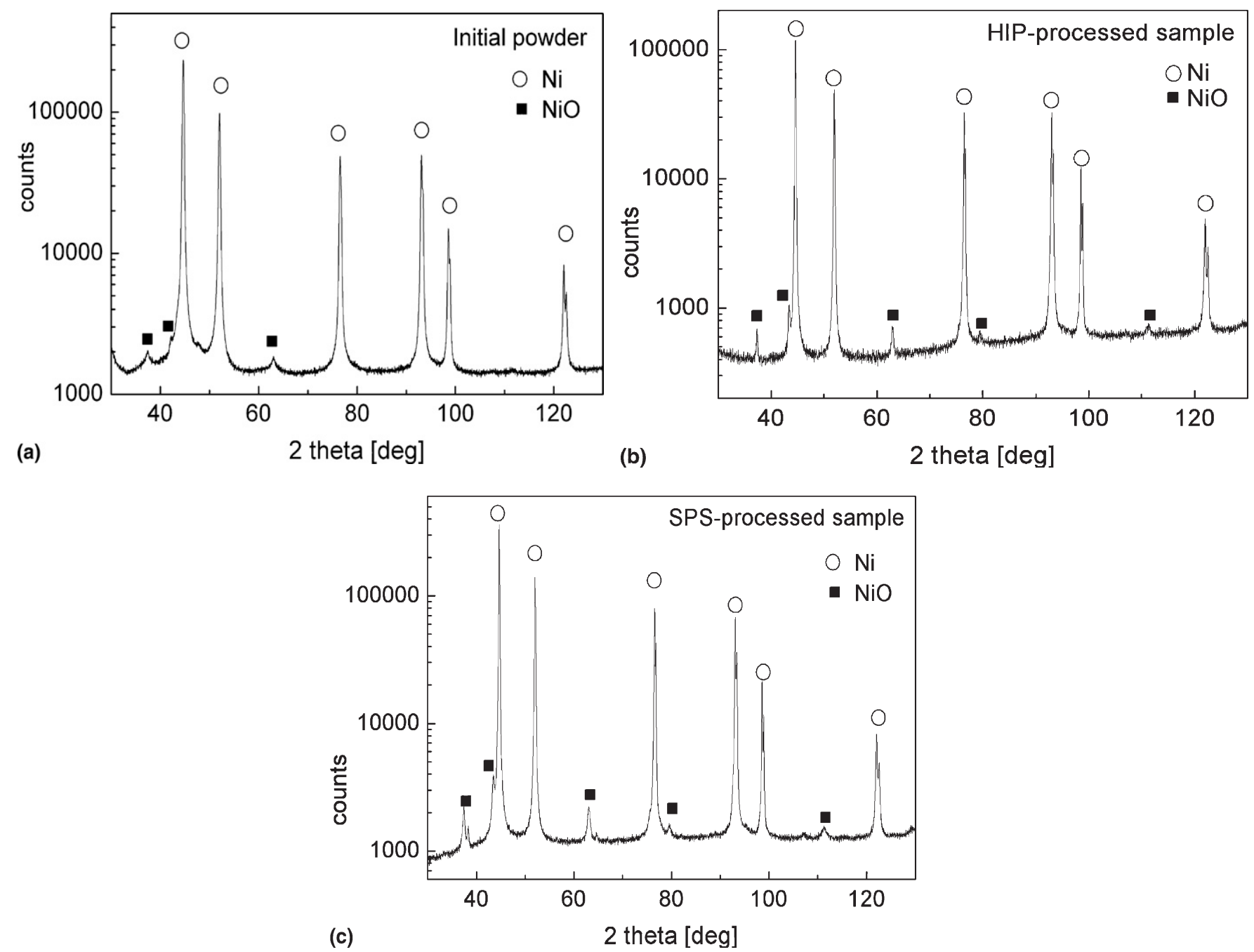

FIG. 2. X-ray diffraction patterns in logarithmic intensity scale for the (a) initial powder and the samples consolidated by (b) HIP and (c) SPS methods.

TABLE I. The intensity ratio $\left(\mathrm{I}_{\mathrm{NiO}} / \mathrm{I}_{\mathrm{Ni}}\right)$ of the $\mathrm{x}$-ray peaks for $\mathrm{NiO}$ and $\mathrm{Ni}$ at $2 \Theta=37.4^{\circ}$ and $44.6^{\circ}$, respectively, the mean grain size $\left(\mathrm{D}_{\mathrm{TEM}}\right)$ obtained from TEM images, the dislocation density $(\rho)$, the twin-fault probability $(\beta)$, and the yield strength $\left(\sigma_{\mathrm{Y}}\right)$ for the samples processed by HIP and SPS.

\begin{tabular}{lcccrr}
\hline \hline Sample & $\mathrm{I}_{\mathrm{NiO} / \mathrm{I}_{\mathrm{Ni}}[\%]}$ & $\mathrm{D}_{\mathrm{TEM}}[\mathrm{nm}]$ & $\rho\left[10^{14} \mathrm{~m}^{-2}\right]$ & $\beta[\%]$ & $\sigma_{\mathrm{Y}}[\mathrm{MPa}]$ \\
\hline HIP & $0.5 \pm 0.1$ & 403 & $5.6 \pm 0.5$ & $0.32 \pm 0.03$ & $542 \pm 14$ \\
SPS & $0.9 \pm 0.1$ & 294 & $5.1 \pm 0.5$ & $0.29 \pm 0.03$ & $682 \pm 15$ \\
\hline \hline
\end{tabular}

very inhomogeneous due to some reflecting particles larger than $1 \mu \mathrm{m}$. Figures 3(c) and 3(d) also show the distribution of grains containing twins. The relative fractions of twinned grains are 19 and $17 \%$ in the HIP- and SPS-processed specimens, respectively. The size distributions of twinned grains follow the total grain-size distributions for both samples.

The true stress versus true strain curves that were obtained for the two consolidated samples by quasistatic compression at room temperature are presented in Fig. 4. The yield strength values that were determined at $0.2 \%$ plastic strain are listed in Table I. The specimen processed by SPS has a higher yield strength $(682 \pm 15$
$\mathrm{MPa}$ ) than that obtained for the sample consolidated by the HIP method $(542 \pm 14 \mathrm{MPa})$. This may be the result of the higher oxide dispersoid content and/or the smaller grain size of the former specimen. Comparing the mechanical behavior of the two samples, it is revealed that the HIP-processed sample hardens in the whole range of strain, whereas for the SPS-processed specimen the flow stress saturates at a small strain value $(\varepsilon \approx 0.04)$, and after a short plateau the sample softens until rupture. The values of strain to failure were 0.22 and 0.35 for the SPS- and HIP-processed samples, respectively.

To better understand the difference in the mechanical behavior of both samples, the defect structure was also 


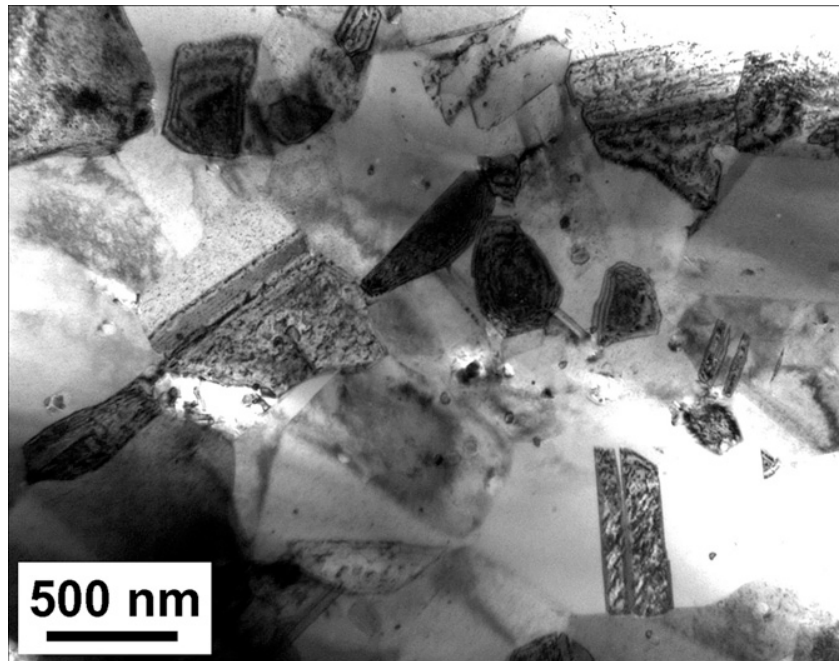

(a)

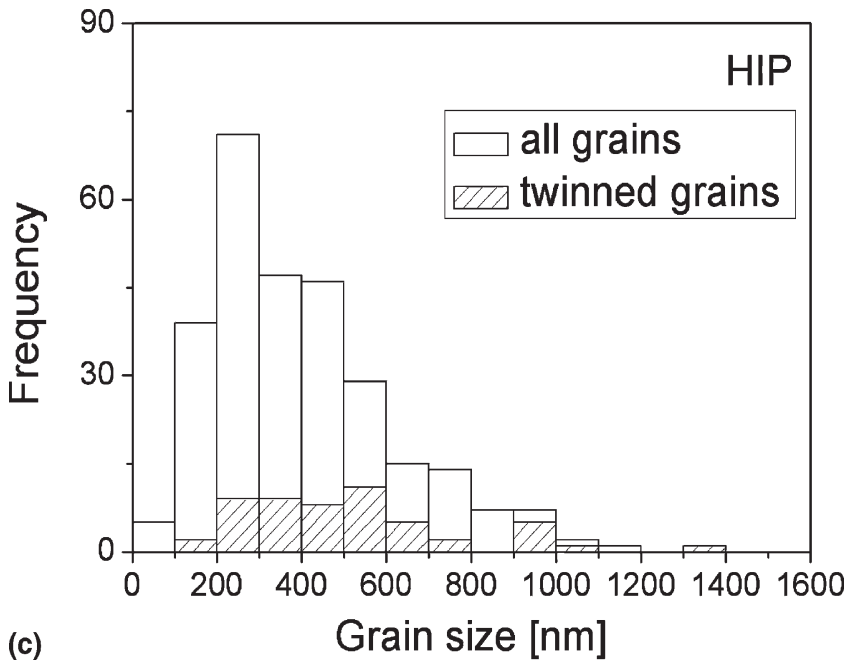

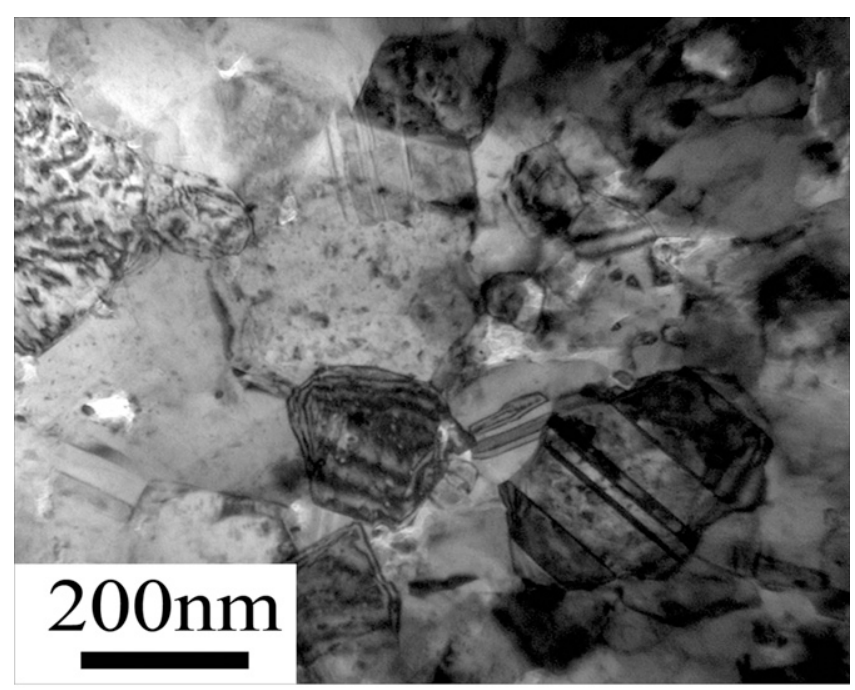

(b)

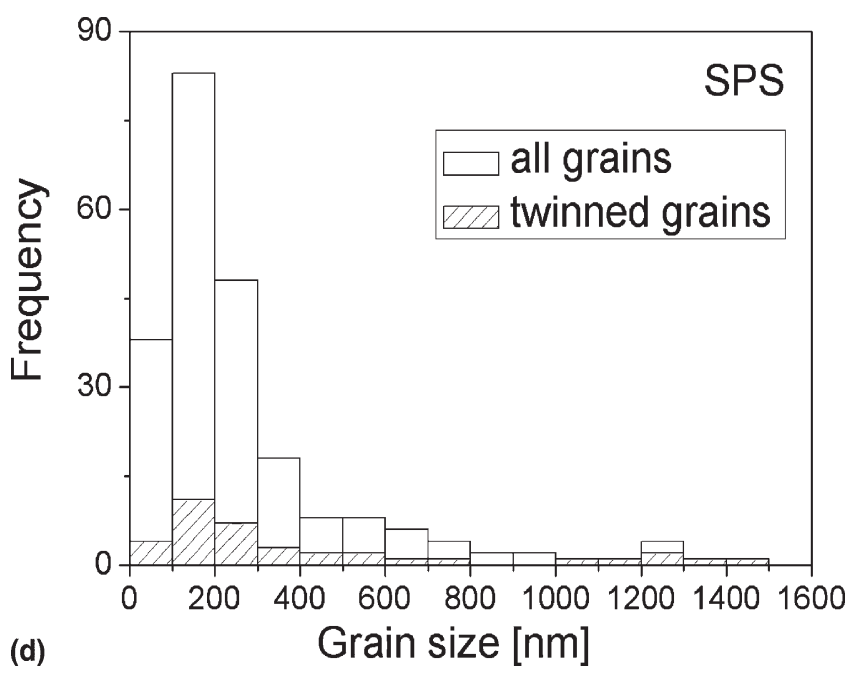

FIG. 3. TEM images of the sample processed by (a) HIP and (b) SPS. Grain-size distributions for the (c) HIP- and (d) SPS-processed bulk samples determined from TEM images. The distributions of twinned grains are also shown by streaked columns.

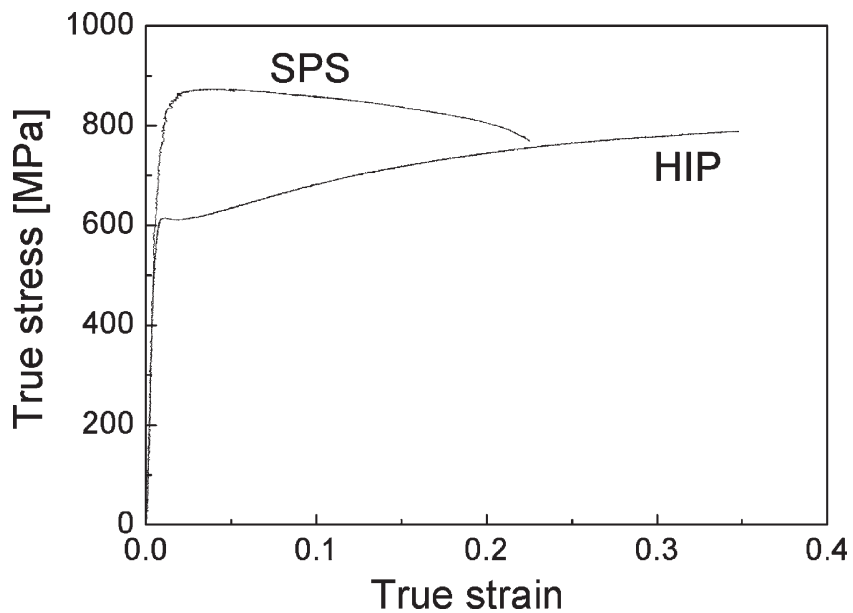

FIG. 4. True stress-true strain curves obtained by compression for the bulk samples processed by HIP and SPS. determined after the compression test by $x$-ray line profile analysis. Figures 5(a) and 5(b) show the dislocation density and twin probability for the HIP- and SPSprocessed samples before and after compression. It can be seen that during room temperature deformation, the dislocation density increased from $5.6 \pm 0.5$ to $16 \pm 2 \times$ $10^{14} \mathrm{~m}^{-2}$ for the HIP-processed sample and from $5.1 \pm 0.5$ to $21 \pm 3 \times 10^{14} \mathrm{~m}^{-2}$ for the SPS-processed specimen. At the same time, the twin probability decreased during compression for both samples: in the case of the HIP-processed sample, it decreased from $0.32 \pm 0.03$ to $0.02 \pm 0.02 \%$, and for the SPS-processed specimen, it decreased from $0.29 \pm 0.03$ to $0.18 \pm 0.02 \%$.

Figures 5(c) and 5(d) show the distribution of the angle of misorientation between the grains in the asconsolidated samples and in the specimens compressed 

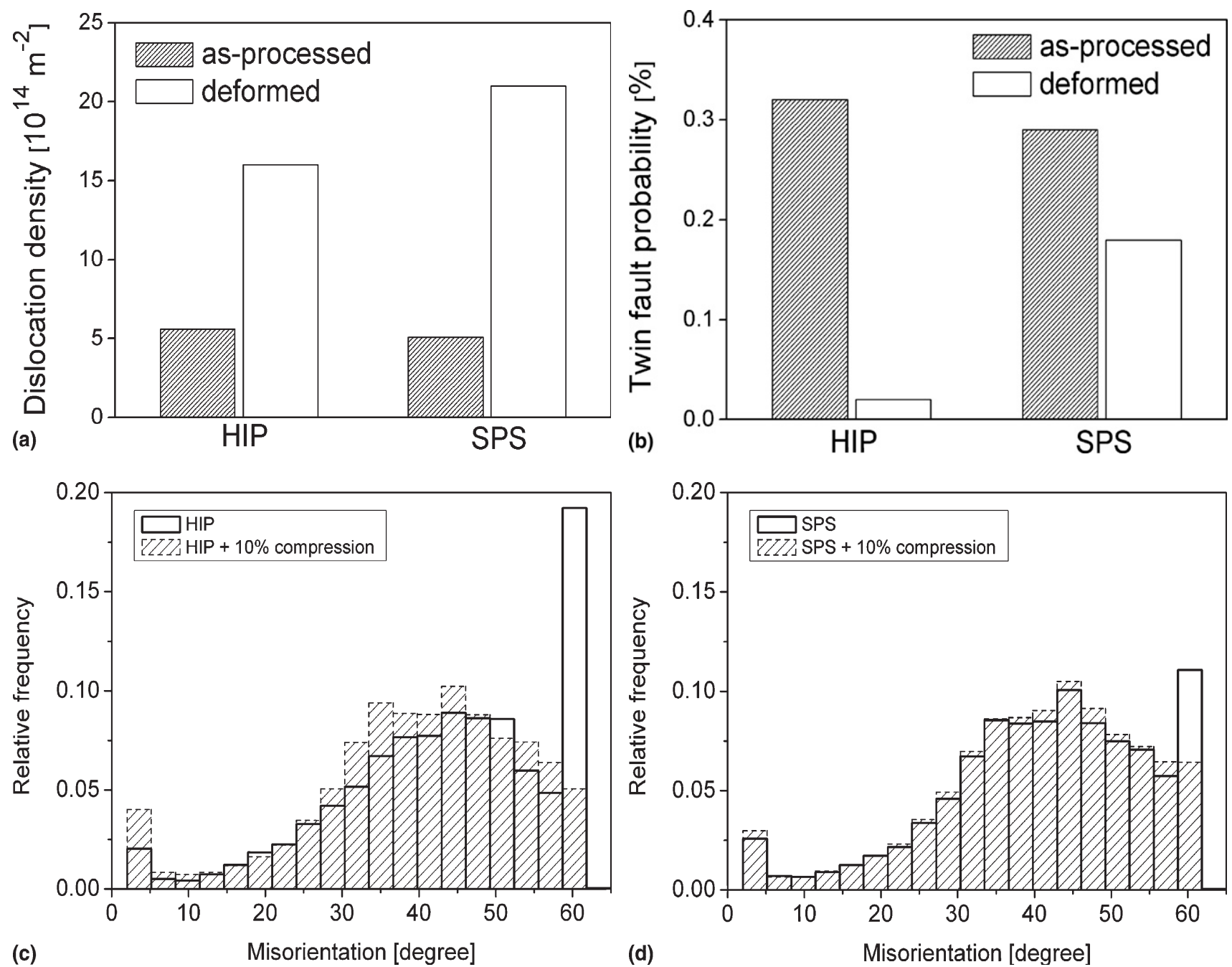

FIG. 5. (a) The dislocation density and (b) the twin fault probability for the HIP- and SPS-processed samples before and after compression test determined by x-ray line profile analysis. The distribution of the angle of misorientation between the grains in the (c) HIP-processed sample and after compression up to $10 \%$ strain and (d) in the SPS-processed sample and after compression up to $10 \%$ strain determined by EBSD.

up to $10 \%$ strain determined by EBSD experiments. For the as-consolidated samples, there is a peak at approximately $60^{\circ}$ in the misorientation distribution, which corresponds to $\Sigma 3$ coincident-site lattice twin boundaries. ${ }^{18,19}$ After compression at $10 \%$ strain, this peak disappeared for both samples, indicating the reduction of densities of twin boundaries. This observation is in agreement with the results of X-ray line profile analysis.

The TEM images in Figs. 6(a) and 6(b) show twin boundaries in large grains after a compression test for the SPS-processed specimen. Figure 6(a) shows steps on twin boundaries denoted by arrows, whereas Fig. 6(b) illustrates the partial disappearance of twin boundaries (arrowed). Inside the white circle in Fig. 6(b) a dislocation pinned by oxide dispersoids is shown.

Figure 7 shows SEM images that were taken on the surface of the SPS-processed sample that was deformed by compression to the strain value of (a) $7 \%$, (b) $18 \%$, and (c) $22 \%$ and the HIP-processed specimen at a strain value of (d) $25 \%$. The loading axis is vertical on the figure. It can be seen that cracks (indicated by arrows) formed in the SPSprocessed sample during compression, and they became more significant with increasing strain. At the same time, no decohesion or crack formation was observed in the HIPprocessed sample that was compressed up to $25 \%$ strain [see Fig. 7(d)]. Figure 8 shows a TEM picture obtained on the SPS-processed sample deformed by compression until failure (up to $22 \%$ strain). This image illustrates that the cracks (arrowed) are formed at the grain boundaries during compression tests.

\section{DISCUSSION}

TEM, EBSD, and x-ray line profile analysis show that both during consolidation of the powder and compression of the consolidated samples, the dislocation density increased while the twin probability decreased, indicating that plastic deformation is basically controlled 


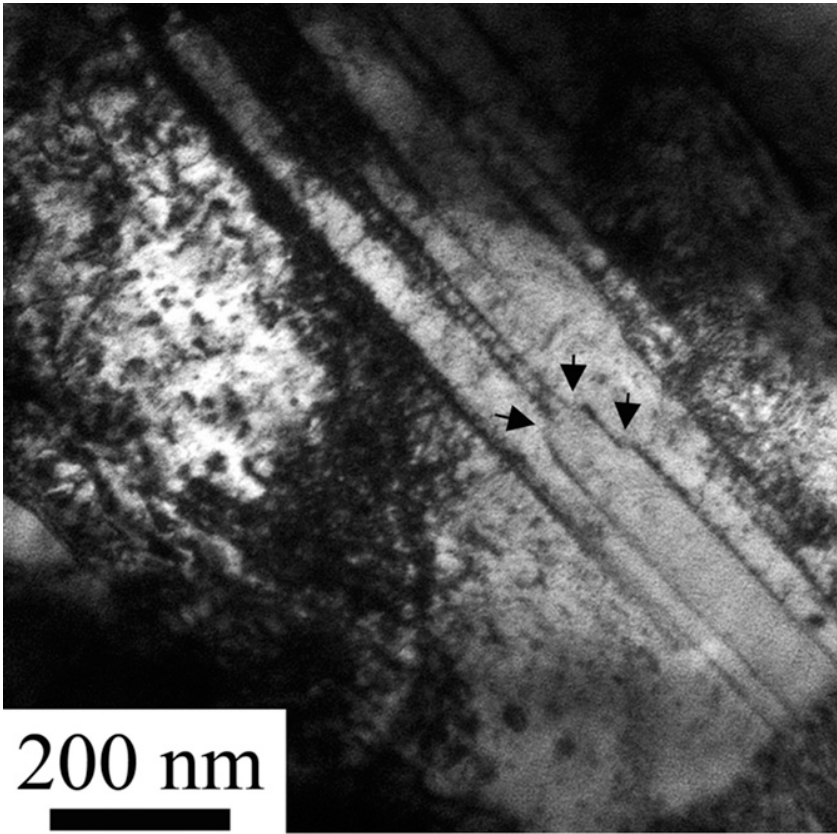

(a)

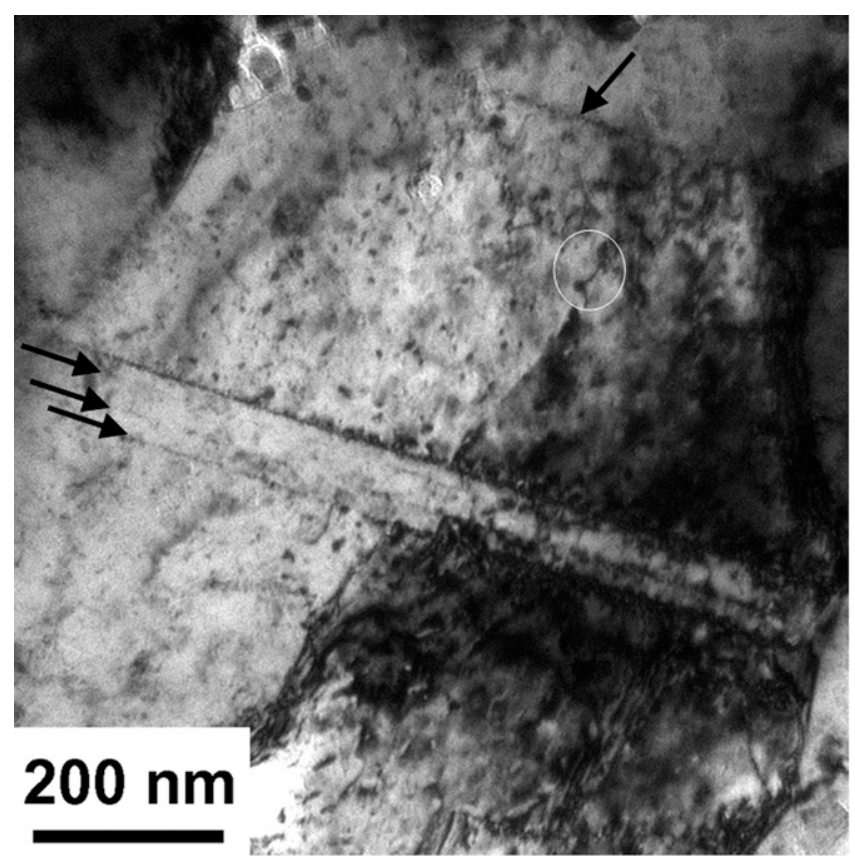

(b)

FIG. 6. TEM images showing twins in large grains after compression test for the SPS-processed sample. The arrows in (a) show steps in twins, whereas in (b) they illustrate the disappearance of twin boundaries. Inside the white circle in (b) a dislocation pinned by oxide dispersoids is shown.

by dislocations. The decrease of the density of twin boundaries has been also reported during cyclic shearstraining of the same specimens. ${ }^{20}$ Previous studies have shown that the reduction of twin density (hereafter referred to as untwinning) is a consequence of an interaction between gliding dislocations and twins. ${ }^{21-23}$ Untwinning has been frequently detected experimentally during plastic deformation in conventional coarse- or ultrafine-grained cubic metals (e.g., in $\mathrm{Cu}^{21}{ }^{21} \mathrm{Ni},{ }^{18}$ and austenitic steel $^{22}$ ), and this process was also observed in nanocrystalline $\mathrm{Al}$ with the grain size of $30-100 \mathrm{~nm}$ by molecular dynamic simulations. ${ }^{23}$ At the same time, previous TEM studies proved that in $\mathrm{Al}$ with a grain size of 10 to $20 \mathrm{~nm}$, twinning became a preferred deformation mode. $^{24,25}$ These observations suggest that in addition to the value of the stacking fault energy, the grain size also has a significant effect on the contributions of the different deformation mechanisms (dislocation glide or twinning) to plastic deformation. According to the literature, because our Ni samples have relatively high stacking fault energy and the mean grain size values are several hundreds of nanometers, the majority of twin boundaries in our samples are most probably growth twins, and the observed untwinning is a result of the interaction between gliding dislocations and pre-existing twin boundaries. However, it is not excluded that mechanical twinning may also occur during plastic deformation in our samples, mainly in the small grains. Nonetheless, the observed decrease of the total twin density suggests that untwinning is more pronounced than twinning.
Previous investigations indicated that the first step of untwinning is usually the dissociation of gliding dislocations into partials at the twin boundaries. ${ }^{26}$ For example, if a dislocation having a Burgers vector of 1/2[101] and gliding on (111) plane reaches a (111) twin boundary, then this dislocation may dissociate into a Shockley-partial and a nonglissile Frank dislocation, such as $1 / 2[101] \rightarrow 1 / 6[1 \overline{2} 1]+1 / 3[111] .^{26}$ Rémy $^{27}$ has shown that other dislocation reactions are also possible at a (111) twin boundary, such as $1 / 2[\overline{1} \overline{1} 0] \rightarrow 1 / 6[1 \overline{2} 1]+1 / 2[011]_{T}$, where the subscript $T$ denotes a dislocation in the twin. Although this dislocation dissociation is energetically unfavorable, it may occur due to a stress concentration at twin boundary-slip band intersections. ${ }^{27}$ The latter reaction produces glissile dislocations: a Shockley-partial in the twin boundary and a lattice dislocation in the twin. If any interaction from the above occurs, a Shockley-partial with the Burgers-vector of $1 / 6[1 \overline{2} 1]$ is formed, which may slip on the (111) plane, resulting in a narrowing of a part of the twin by one (111) lattice spacing. If a slip band intersects a (111) twin boundary, the slipping of Shockleypartials on successive (111) planes yields to partial untwinning (see Fig. 3 in Ref. 22 or Fig. 8 in Ref. 23). Figures 6(a) and 6(b) illustrate the results of the interaction between gliding dislocations and twins during compression in the SPS-processed specimen. The steps on twin boundaries in Fig. 6(a) and the partial disappearance of the arrowed twins in Fig. 6(b) were most likely due to dislocation activity. Similar steps on twin boundaries were 


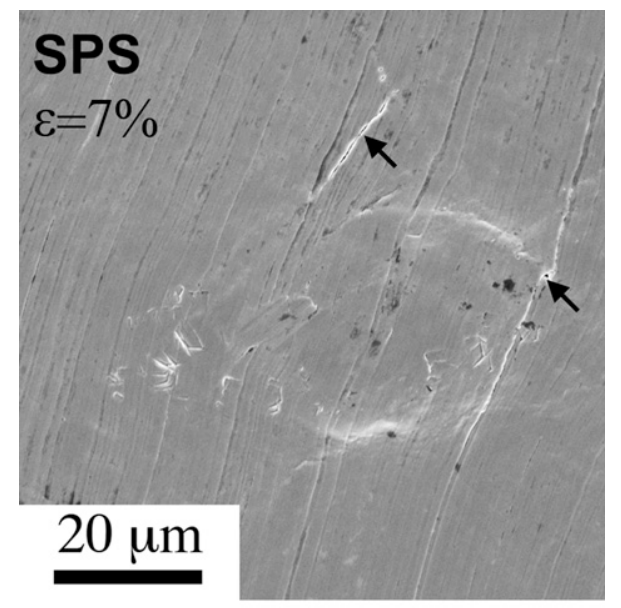

(a)

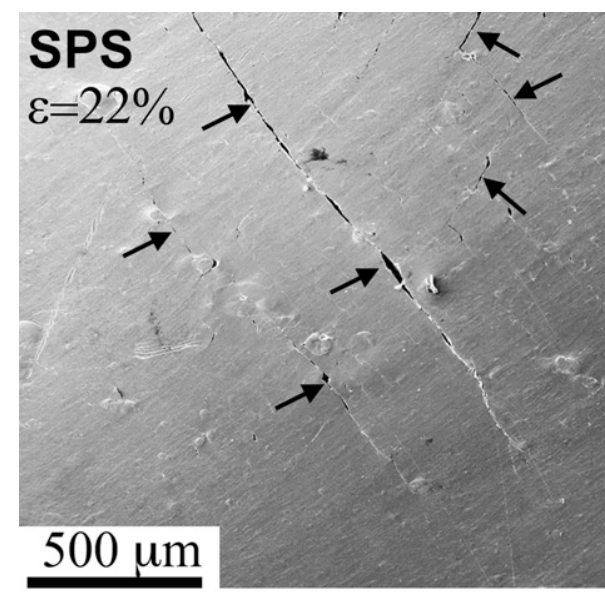

(c)

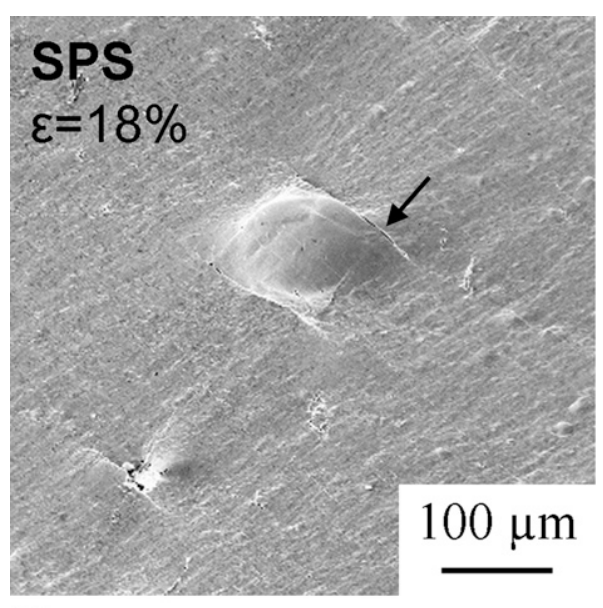

(b)

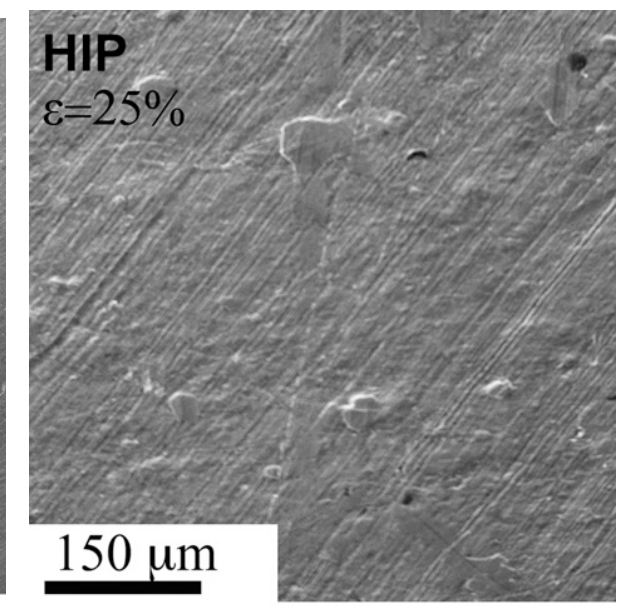

(d)

FIG. 7. SEM images showing the surface of the SPS-processed sample deformed by compression to the strain values of (a) $7 \%$, (b) $18 \%$, and (c) $22 \%$ and (d) the surface of the HIP-processed specimen at a strain of $25 \%$. The loading axis is vertical in the figure.

also previously observed in plastically deformed $\mathrm{Cu}$ (see Fig. 7 in Ref. 28). In general, in our samples, we noted that untwinning can only be observed in large grains that have grain sizes higher than approximately $500 \mathrm{~nm}$. This result is in agreement with previous observations in the literature: the larger the grain size, the higher the contribution of dislocations to plastic deformation in Ni.

Figures 3(c) and 3(d) show that the size distribution of grains containing twins follows the total grain size distribution in both consolidated samples. Because the HIPprocessed sample has larger grains [compare Figs. 3(c) and 3(d)] and untwinning mainly occurred in large grains, the decrease of twin probability during compression is expected to be higher for the HIP-processed sample. This is in agreement with the experimental results of x-ray line profile analysis, which shows that the reduction of twin probability is much higher for the HIP-processed sample than for the SPS-processed specimen [see Fig. 5(b)]. In the latter sample, the plastic deformation of the small grains may be partially mediated by grain boundary-related mechanisms, such as grain boundary sliding and/or grain rotation $^{29-31}$ or mechanical twinning. ${ }^{24,25}$ It is noted that the larger strain to failure for the HIP-processed sample may also contribute to the higher degree of untwinning in this specimen.

Figure 4 shows that the mechanical behavior of the UFG Ni samples consolidated by HIP and SPS methods are significantly different. The higher compressive yield strength of the SPS-processed specimen can be attributed to the smaller grain size and the higher content of $\mathrm{NiO}$ dispersoids compared with the sample produced by HIP (see Table I). The smaller grain size is due to the reduced temperature and time of SPS procedure, whereas the higher $\mathrm{NiO}$ content resulted from the processing of the powder in air. Dislocations and twin boundaries in the consolidated samples also increase the strength because they act as obstacles against dislocation motion. However, they should have similar hardening effects in the two specimens because the dislocation densities and twin-fault probabilities are nearly the same after SPS and 


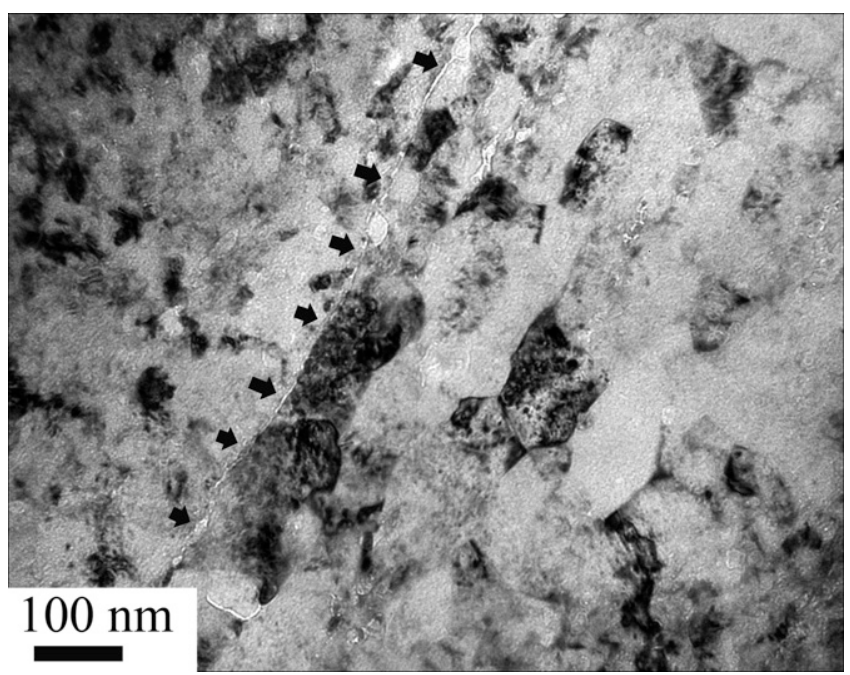

FIG. 8. TEM image showing a long crack (arrowed) along the grain boundaries of ultrafine grains in the SPS-processed sample deformed up to failure.

HIP procedures (see Table I), in spite of the lower temperature and time of the SPS processing. It is noted that in both processes, the level of the applied pressure is almost the same.

In the beginning of compression test, the strain hardening for the SPS-processed sample is larger and the flow stress saturates at a relatively low strain value $(\varepsilon \approx 0.04$, see Fig. 4). This can be explained by the larger fraction of oxide dispersoids, which interact with the dislocations emitted from grain boundaries, leaving dislocation loops around the particles, and thereby increasing the dislocation density quickly. ${ }^{32}$ It is noted that the low strain value at saturation does not exclude a high value of the saturated dislocation density, as can be seen in the sample processed by SPS $\left(21 \pm 3 \times 10^{14} \mathrm{~m}^{-2}\right)$. After saturation of the flow stress, strain softening occurs during deformation of the SPS-processed sample, whereas the HIP-processed specimen hardens until failure (see Fig. 4). Figures 7 and 8 show that cracking occurs at the grain boundaries of the specimen processed by SPS even at a strain of 0.07 , and the concentration and length of cracks increased with increasing strain. At the same time, for the HIP-processed specimen cracking was not observed even at a strain of 0.25 . The crack formation is most likely the reason for flow softening during compression test and the smaller strain until failure in the SPS-processed sample. The crack formation can be attributed to grain boundary-related deformation processes, which may be more pronounced for the SPS-processed sample due to its smaller grain size. The other reason for cracking could be the higher flow stress level during deformation of the SPS-processed sample, which results in a larger probability of debonding between the grain boundaries. In addition, it should be noted that the higher total oxide content in the SPS-processed sample probably involves higher oxide content on the grain boundaries, which may reduce the grain boundary strength, resulting in easier cracking during deformation. ${ }^{33}$

\section{CONCLUSIONS}

The microstructure and the mechanical behavior of ultrafine-grained Ni samples consolidated from a nanopowder by two different methods were studied. It was found that starting from the same powder, the SPS method resulted in a moderated grain-growth compared with the HIP procedure due to the reduced processing time and temperature. Moreover, the SPS-processed sample has a higher oxide phase content because during this procedure the powder was transferred from the capsule to the mould in air. The HIP-processed sample showed a strain-hardening behavior up to the rupture of the specimen, and in this sample the twin-fault probability decreased drastically during deformation as a consequence of the interaction between twins and gliding dislocations. In the SPS-processed sample, the higher concentration of oxide dispersoids and the smaller grain size resulted in a higher yield strength and an early saturation of the flow stress during compression. The further strain softening is attributed to cracking, which is most likely a consequence of high flow stress level and weak boundary strength influenced by the presence of oxides.

\section{ACKNOWLEDGMENTS}

We are grateful for the support of the Hungarian TeT Foundation (KPI) under Contract No. F-47/2006 (Balaton project). This work was supported by the Hungarian Scientific Research Fund, OTKA, Grant Nos. K67692 and K71594. J.G. is grateful for the support of a Bolyai Janos Research Scholarship of the Hungarian Academy of Sciences and the help of Noemi Szasz in X-ray diffraction experiments. G.F.D. is grateful for the support of ÉGIDE, in the framework of the Hubert Curien Project (PHC Balaton).

\section{REFERENCES}

1. V.M. Segal: Materials processing by simple shear. Mater. Sci. Eng., A 197, 157 (1995).

2. R.Z. Valiev, R.K. Islamgaliev, and I.V. Alexandrov: Bulk nanostructured materials from severe plastic deformation. Prog. Mater. Sci. 45, 103 (2000).

3. R.Z. Valiev, Y. Estrin, Z. Horita, T.G. Langdon, M.J. Zehetbauer, and Y.T. Zhu: Producing bulk ultrafine-grained materials by severe plastic deformation. JOM 58, 33 (2006).

4. A. Dubravina, M.J. Zehetbauer, E. Schafler, and I.V. Alexandrov: Correlation between domain size obtained by $\mathrm{x}$-ray Bragg profile analysis and macroscopic flow stress in severely plastically deformed copper. Mater. Sci. Eng., A 387-389, 817 (2004).

5. P.G. Sanders, C.J. Youngdahl, and J.R. Weertman: The strength of nanocrystalline metals with and without flaws. Mater. Sci. Eng., A 234-236, 77 (1997). 
6. H.V. Atkinson and S. Davies: Fundamental aspects of hot isostatic pressing: An overview. Metall. Mater. Trans. A 31, 2981 (2000).

7. Y. Champion, F. Bernard, N. Guigue-Millot, and P. Perriat: Sintering of copper nanopowders under hydrogen: An in situ X-ray diffraction analysis. Mater. Sci. Eng., A 360, 258 (2003).

8. J. Gubicza, G. Dirras, P. Szommer, and B. Bacroix: Microstructure and flow stress of ultrafine grained aluminum processed by hot isostatic pressing. Mater. Sci. Eng., A 458, 385 (2007).

9. S. Billard, J.P. Fondere, B. Bacroix, and G.F. Dirras: Macroscopic and microscopic aspects of the deformation and fracture mechanisms of ultrafine-grained aluminum processed by hot isostatic pressing. Acta Mater. 54, 411 (2006).

10. W. Chen, U. Anselmi-Tamburini, J.E. Garay, J.R. Groza, and Z.A. Munir: Fundamental investigations on the spark plasma sintering/synthesis process: I. Effect of dc pulsing on reactivity. Mater. Sci. Eng., A 394, 132 (2005).

11. R. Chaim: Densification mechanisms in spark plasma sintering of nanocrystalline ceramics. Mater. Sci. Eng., A 43, 25 (2007).

12. M. Trunec, K. Macaa, and Z. Shen: Warm pressing of zirconia nanoparticles by the spark plasma sintering technique. Scr. Mater. 59, 23 (2008).

13. S. Paris, E. Gaffet, F. Bernard, and Z.A. Munir: Spark plasma synthesis from mechanically activated powders: A versatile route for producing dense nanostructured iron aluminides. Scr. Mater. 50, 691 (2004).

14. F. Tepper: Electro-explosion of wire produces nanosize metals. Met. Powder Rep. 53, 31 (1998).

15. Y. Kwon, Y. Jung, N. Yavorovsky, and A. Illyn: Ultra-fine powder by wire explosion method. Scr. Mater. 44, 2247 (2001).

16. G. Ribárik, J. Gubicza, and T. Ungár: Correlation between strength and microstructure of ball milled $\mathrm{Al}-\mathrm{Mg}$ alloys determined by x-ray diffraction. Mater. Sci. Eng., A 387-389, 343 (2004).

17. L. Balogh, G. Ribárik, and T. Ungár: Stacking faults and twin boundaries in fcc crystals determined by x-ray diffraction profile analysis. J. Appl. Phvs. 100, 023512 (2006).

18. A.P. Zhilyaev, B-K. Kim, J.A. Szpunar, M.D. Baro, and T.G. Langdon: The microstructural characteristics of ultrafinegrained nickel. Mater. Sci. Eng., A 391, 377 (2005).

19. Y. Zhao, T. Topping, J.F. Bingert, J.J. Thornton, A.M. Dangelewicz, Y. Li, W. Liu, Y. Zhu, Y. Zhou, and E.J. Lavernia: High tensile ductility and strength in bulk nanostructured nickel. Adv. Mater. 20, 3028 (2008).
20. B. Hasni: Mechanical characterization of fine-grained materials subjected to large deformations under monotoneous and cyclic stresses. M.Sc. Thesis, University of Paris, Paris, France, 2007.

21. D.P. Field, B.W. True, T.M. Lillo, and J.E. Flinn: Observation of twin boundary migration in copper during deformation. Mater. Sci. Eng., A 372, 173 (2004).

22. P. Müllner and C. Solenthaler: On the effect of deformation twinning on defect densities. Mater. Sci. Eng., A $\mathbf{2 3 0}$, 107 (1997).

23. V. Yamakov, D. Wolf, S.R. Phillpot, and H. Gleiter: Dislocationdislocation and dislocation-twin reactions in nanocrystalline $\mathrm{Al}$ by molecular dynamics simulation. Acta Mater. 51, 4135 (2003).

24. M. Chen, E. Ma, K.J. Hemker, H. Sheng, Y. Wang, and $X$. Cheng: Deformation twinning in nanocrystalline aluminium. Science 300, 1275 (2003).

25. A. Froseth, H. Van Swygenhoven, and P.M. Derlet: The influence of twins on the mechanical properties of nc-Al. Acta Mater. $\mathbf{5 2}$. 2259 (2004).

26. L. Lu, Y. Shen, X. Chen, L. Qian, and K. Lu: Ultrahigh strength and high electrical conductivity in copper. Science 304, 422 (2004).

27. L. Rémy: Twin-slip interaction in f.c.c. crystals. Acta Metall. 25. 711 (1977).

28. L. Lu, R. Schwaiger, Z.W. Shan, M. Dao, K. Lu, and S. Suresh: Nano-sized twins induce high rate sensitivity of flow stress in pure copper. Acta Mater. 53, 2169 (2005).

29. I.A. Ovidko: Deformation of nanostructures. Science 295, 2386 (2002).

30. D. Jia, K.T. Ramesh, and E. Ma: Effects of nanocrystalline and ultrafine grain sizes on constitutive behavior and shear bands in iron. Acta Mater. 51, 3495 (2003).

31. I. Sabirov, Y. Estrin, M.R. Barnett, I. Timokhina, and P.D. Hodgson: Tensile deformation of an ultrafine-grained aluminium alloy: Micro shear banding and grain boundary sliding. Acta Mater. 56, 2223 (2008).

32. F.J. Humphreys and J.W. Martin: The effect of dispersed phases upon dislocation distributions in plastically deformed copper crystals. Philos. Mag. 16, 927 (1968).

33. L.J. Kecskes, K.C. Cho, R.J Dowding, B.E. Schuster, R.Z. Valiev, and Q. Wei: Grain size engineering of bcc refractory metals: Top-down and bottom-up-Application to tungsten. Mater. Sci. Eng., A 467, 33 (2007). 